\title{
РАЗВИТИЕ СЕЛЬСКИХ ПРОМЫСЛОВ В СОВРЕМЕННЫХ УСЛОВИЯХ
}

\author{
(c) 2020 Пекуровский Д.А. \\ кандидат военных наук, доцент \\ Российская академия кадрового обеспечения агропромышленного комплекса, Россия, Москва \\ E-mail: agor80@yandex.ru \\ (c) 2020 Багмут C. B. \\ кандидат экономических наук, старший преподаватель кафедры институциональной \\ экономики и инвестиционного менеджмента \\ Кубанский государственный аграрный университет имени И. Т. Трубилина, Россия, Краснодар
}

Статья посвящена структурному анализу промыслового дела в сельской местности. Автором рассмотрены основные тенденции сельской экономики, приведен исторический анализ традиционных сельских промыслов. В результате исследования сформулирован вывод о необходимости развития сельских промыслов для диверсификации сельской экономики и роста благосостояния жителей в институциональной форме потребительской кооперации.

Ключевые слова: агротуризм; пандемия; потребительская кооперация; сельские промыслы; сельский туризм.

В российском селе в настоящее время протекает активный процесс изменения специфичных особенностей экономических отношений, выражающийся в ряде структурных изменений, связанных с взаимодействием различных институциональных субъектов. В этих условиях большой значимостью обладает вопрос о сохранении сельских промыслов, которые являются для сельского населения как альтернативным источником получения дохода, так и средством сохранения социокультурного единства $[15$, с. 326].

При рассмотрении вопроса о сельских промыслах необходимо исходить в первую очередь из текущих экономических реалий, поскольку возникновение и существование промыслов всегда было обусловлено характером экономических отношений. Мы полагаем, что полноформатное возрождение сельских промыслов в их исконном варианте не представляется возможным ввиду качественного изменения экономической системы государства.

Рассмотрим промысловую экономику крестьянской деревни конца XIX века на примере Царскосельского уезда Санкт-Петербургской губернии. Большая часть крестьян предпочитала заниматься промыслами в территориальных рамках своей волости. Так, 17\% мужчин и 55\% женщин были заняты сельскими промыслами на территории деревни, 35\% мужчин и 23\% женщин осуществляли промыслен на территории волости. В рамках уезда занимались промыслами лишь 18,6\% мужчин и 6\% женщин [4, с. 97]. Большое развитие получили деревообрабатывающий промысел, ломка плиты по берегам p. Пудость, гончарный промысел, извозный промысел, дачный промысел (приспособление домов под дачные помещения и их сдача на летний период столичным обывателям). Однако, главным промыслом был лесной промысел - заготовка и вывоз дров и бревен имел существенную роль в хозяйственной жизни населения. Имели и малораспространенные в силу географических особенностей промыслы - в частности, судовой промысел [4, с. 95]. Промыслы составляли одну из основ сельской экономики. Исключительно лишь земледелием занималось малое количество крестьян. Так, в Гатчинской волости только земледелием занималось $1,8 \%$ крестьян, только промыслом - 11,5\% крестьян, земледелием и промыслами - 86,7\% крестьян. С целью структурной организации земледелия и промыслов, а также разделения труда действовали крестьянские промыслово-земледельческие дворы $[4$, с. 91].

В настоящее время возрождение прежней системы промыслов не является необходимым, поскольку, во-первых, изменился характер занятости сельского населения (сельские работники трудятся на предприятиях АПК, в сфере обслуживания и др.), во-вторых, продукция сельских промыслов не играет столь значимой 
роли в экономике (в рамках производственных предприятий бизнес-процессы протекают с большей эффективностью), в-третьих, исчезли необходимые для полноценной организации промыслов институциональные субъекты (промыслово-земледельческие дворы). Вместе с этим, сельский уклад дает большое число возможностей для ведения традиционных и художественных промыслов, что содержит в себе существенный экономический потенциал [10, с. 164]. Тем не менее, структурное изменение промысловой экономики не означает ее уничтожения. «Парадокс заключается в том,- пишет Е. Н. Филиппова, - что в современной России параллельно сосуществуют два уклада, две крайности, два разных мира. Один из них - реальный мир промыслов, в котором живет вся сельская глубинка, это - начальный технологический уклад, другой - мир современных технологий, прогресса, высоких технологий, это - перспектива, связанная с попаданием в число развитых стран, в пятый и шестой технологические уклады» [12, с. 115]». Многоукладность современной экономической системы допускает вероятность существования отдельного сельского уклада [16, с. 658]. Однако, одна из общих тенденций состоит в увеличении веса крупных промышленноэкономических и земельных сил за счет положения сельских жителей. В.С.Шмаков пишет о поляризации производственно-экономического и социально-культурного пространства российского села. Развитие латифундий сопровождается упадком традиционных форм организации сельскохозяйственной экономики [13, с. 342].

Несмотря на продолжающиеся изменения, сельские районы по-прежнему характеризуются относительным обилием природного капитала, а также удаленностью и относительно высокой стоимостью передвижения. По сравнению с городскими районами, которые находятся недалеко от покупателей и производителей, сельские районы могут иметь сравнительные преимущества только в основных видах деятельности, основанных на природных ресурсах. Однако, существуют различия между пригородными, сельскими и отдаленными районами. В некоторых областях экономический рост, расширение городов, улучшение транспорта и связи создают новые ориентированные на город возможности для сельских услуг и рабочей силы. Однако отдаленные районы по-прежнему будут представлять особые трудности.
Сельские районы больше не связаны исключительно с производством сельскохозяйственных товаров, а рассматриваются как места для стимулирования новой социальноэкономической деятельности, часто включающей туризм, досуг, производство, а также электронную торговлю.

Развитие сельских промыслов может идти по пути возрождения и модернизации. Л.А. Киркорова, К.Н.Ларичева к модернизированным сельским промыслам предлагается отнести альтернативные направления российского охотничьего и рыбоводного фермерства, которое предполагает комплексное и рациональное использование сельскохозяйственных угодий, земель лесного и водного фонда, а также биоресурсов животного мира (промысловых объектов охоты и рыбалки) [3, с. 102]. Тем не менее, мы полагаем, что целенаправленная модернизация промыслов является скорее экзотикой, нежели необходимостью. Для существования промыслов имеются все необходимые экономические предпосылки. Е.Н.Филиппова в качестве особенностей сельской деятельности, способствующих развитию промыслового дела, называет:

- Низкая доля предпринимательства (биоресурсы используются преимущественно населением);

- Неразрывная (как правило) связь с сельхозпроизводством;

- Историческая связь с местом проживания;

- Сезонность работ;

- Наличие ряда объективных ограничений деятельности (небольшое производство, малое предпринимательство и др.) [11, с. 140].

Сельские промыслы с некоторой долей условности можно разделить на различные виды. Так, Е.В.Кандрина выделяет существование в Мордовии следующих промыслов:

- Традиционные «кустарные» промыслы (горшечное, кузнечное, валяльное, бондарное, плотницкое);

- Художественные промыслы (ручное ткачество, плетение кружев, производство художественных керамических изделий, художественная обработка металла) [2, с. 118].

Кустарные промыслы являются ремеслом. Ключевое различие ремесленного дела прошлого и настоящего заключается в том, что ранее ремесленники удовлетворяли массовый спрос, сегодня же ремесленная продукция играет роль эксклюзива. Сельские ремесла относятся к тра- 
диционным ремеслам и не считаются частью декоративно-прикладного искусства, поскольку они производятся для практических потребностей, а не для отдыха, эстетики и рекреации. В общем и целом, ремесло - это преобразующая деятельность, ремесленники производят товары с помощью традиционных технических знаний и использования простых инструментов. Ремесло выделяется как социально-экологическая система, которая связывает производственную деятельность (и необходимые природные ресурсы) с материальным и нематериальным наследием сельского сообщества. С этой точки зрения ремесло можно рассматривать как социальную систему, которая может противостоять вызовам глобализации. Ремесленничество, которое иногда называют кустарным ремеслом и ручной работой, является любым из широкого спектра видов работ, где полезные и декоративные элементы сделаны полностью вручную или с помощью только простых инструментов. Это традиционная основная отрасль ремесла, которая применяется в широком спектре творческих и дизайнерских мероприятий, связанных с созданием вещей своими руками и навыками, включая работу с текстилем, формуемыми и жесткими материалами, бумагой, растительными волокнами и др.

Одним из наиболее перспективных направлений развития сельских промыслов является агротуризм (сельский туризм). М.В.Пономарева, А. О. Чернобровкина определяют агротуризм как вид экологического туризма, представляющий собой активный отдых человека в природной среде с использованием ее природных, рекреационных и иных возможностей при условии сохранения и приумножения природных богатств. В качестве структурного ядра агротуризма исследователи видят событийные мероприятия, которые получили развитие в Тульской области [6, с. 59]. Существование сельского туризма предлагается подтвердить на законодательном уровне. Согласно проекту Федерального закона № 690944-7 «О внесении изменений в отдельные законодательные акты Российской Федерации по вопросам развития сельского туризма (агротуризма)», сельский туризм (агротуризм) - это разновидность туризма, предполагающая временные выезды к отечественному сельскохозяйственному товаропроизводителю [7].

В ряде регионов России имеется большой положительный опыт развития агротуризма. К примеру, на территории Алтайской республики туризм получил большое распространение по причине уникальных географо-климатических условий и самобытной культуры коренных народов. Г.М.Патрушева к сельскому туризму в Республике Алтай причисляет сплав по горным рекам, рыбалку, конный прокат, туристские поездки по различным местах и объектам (целительные ключи, сакральные природные объекты, водопады, пещеры, долины). Г.М. Патрушева отмечает, что нереализованным потенциалом обладают народные праздники и художественные промыслы [5, с. 87].

Любые формы туризма, которые демонстрируют сельскую жизнь, искусство, культуру в сельской местности, тем самым принося пользу местному локальному сообществу в экономическом и социальном плане, фактически являются сельским туризмом. Сельский туризм позволяет наладить взаимодействие между туристами и сельским населением.

Для описания туристической деятельности в сельской местности используются различные термины: агротуризм, фермерский туризм, сельский туризм, альтернативный туризм, экотуризм. Виды и формы сельского туризма следующие:

- Агротуризм

Хотя термин «агротуризм» часто используется для описания всей туристической деятельности в сельской местности, чаще термин относится к туристическим продуктам, которые напрямую связаны с аграрной средой, сельскохозяйственными продуктами, проживанием туристов в сельской местности.

- Фермерский туризм

Данный вид туризма напрямую связан с фермерским хозяйством и чаще всего с туризмом, включающим проживание в деревенских хозяйствах.

- Природный туризм (туризм в дикой природе)

В рамках природного туризма турист исследует дикую природу и красоту сельской местности. Это понятие может рассматриваться в отдельности от агротуризма, однако исследователи склонны отождествлять природный туризм и агротуризм (к примеру, сплав по горным реками обычно рассматривается в качестве агротуризма). Туризм в дикой природе и лесах включает в себя различные туристические ме- 
роприятия, такие как охота и рыбалка, сплав по рекам, путешествия и др.

- Зеленый туризм

Зеленый туризм относится к туризму в сельской местности или зеленых зонах. Он чаще используется для описания форм туризма, которые считаются более экологически безопасными, чем традиционный массовый туризм [14, c. 2363]. В сельской местности зеленый туризм является важной формой туризма.

\section{- Экотуризм}

Это форма природного туризма, который предполагает активное содействие сохранению окружающей среды и получение прямых выгод для местных сообществ и культур, а также предоставление туристам положительного познавательного опыта. Экотуризм - это группа устойчивых туристических мероприятий, происходящих в естественной среде.

Развитие тех или иных форм сельского туризма должно сопровождаться объективным анализом экономической обстановки и совокупности географо-климатических факторов.

Развитие сельских промыслов требует иного подхода к их институциональной составляющей. Институциональные формы объединения должны быть построены на принципах свободы, добровольности участия, поощрения творческой инициативы [9, с. 41]. На сегодняшний день основными институциональными объединениями являются АПК и крестьянские (фермерские) хозяйства. Хозяйства населения сложно рассматривать в качестве полноценного институционального субъекта, поскольку они организованы по семейному, а не профессиональному признаку. Тем не менее, домашние хозяйства вбирают в себя сельскую инициативы, и развитие промыслов не представляется возможным без наличия крепких хозяйств. Основными препятствиями на пути развития хозяйств является дороговизна кормовой базы и существенные затруднения при сбыте продукции. На рис. 1 представлена структура продукции сельского хозяйства по субъектам (категориям хозяйств) [8], наглядно свидетельствующая о снижении численности домашних хозяйств. Впрочем, рост численности и ее снижение можно рассматривать в качестве единой волны продолжительностью в три десятилетия. К сожалению, в России не были созданы экономические условия для поддержания сельских хозяйств, в 2019 году их число снизились по отношению к уровню 1991 года.

В рамках имеющегося законодательного поля построение промыслового уклада возможно лишь в рамках потребительской кооперации. Согласно ст. 1 Закона РФ от 19.06.1992 № 3085-1 «О потребительской кооперации (потребительских обществах, их союзах) в Российской Федерации» потребительским обществом является добровольное объединение граждан и (или) юридических лиц, созданное, как правило, по территориальному признаку, на основе членства путем объединения его членами имущественных паевых взносов для торговой, заготовительной, производственной и иной деятельности в целях удовлетворения материальных и иных потребностей его членов [1]. Потребительская кооперация позволит создать удобную форму отношений между производителями.

Пандемия 2020, безусловно, отрицательно сказывается на развитии сельских промыслов. Наибольшим образом пострадал сельский ту-

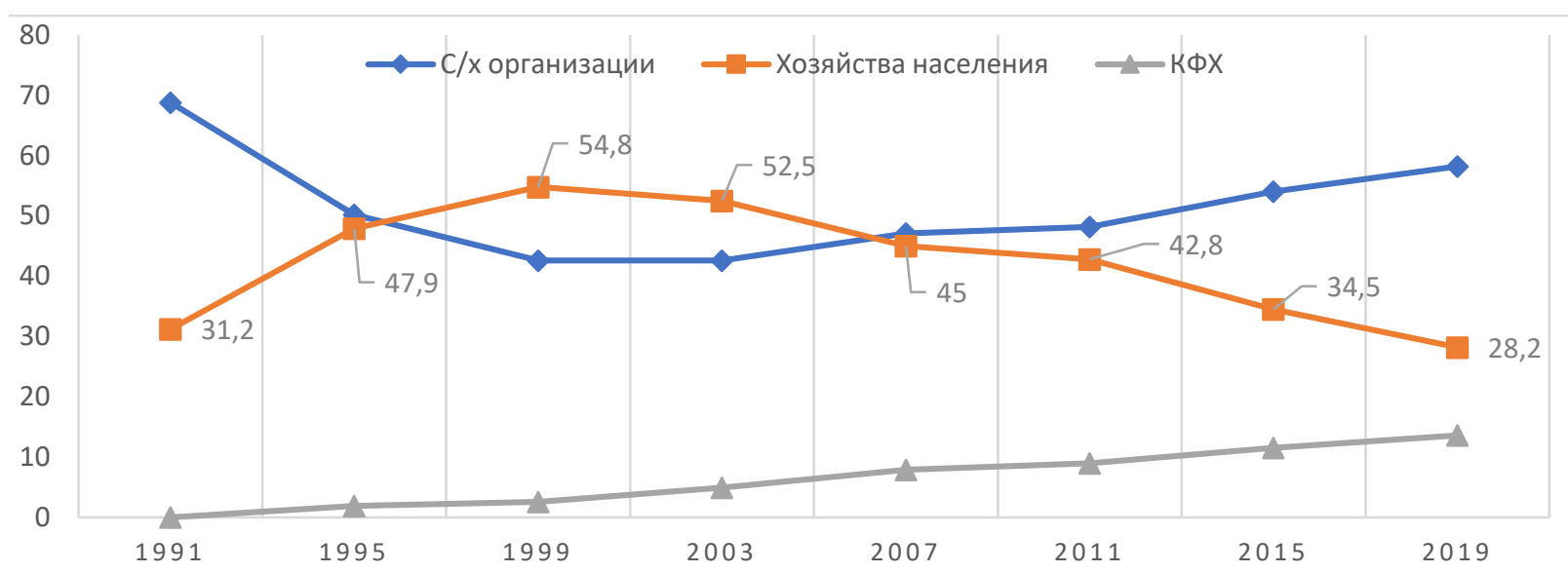

Puc. 1. Структура сельского хозяйства по категориям хозяйств по РФ за период 1991-2019 годы 
ризм, поскольку туристические потоки в первые месяцы борьбы с COVID 19 остановились ввиду введения ограничений на передвижение граждан. Необходимость соблюдения карантина при перемещении между субъектами федерации, электронные пропуска в отдельных регионах, и, самое главное, прямой запрет на свободное передвижение полностью пресекли агротуризм. Что же касается непосредственно сельских промыслов, то здесь в первую очередь пострадали производители сельскохозяйственной продукции (животноводство и растениеводство). В сложном положении оказались также представители ремесленного дела, поскольку возможности для сбыта продукции существенно ограничились. Поэтому, в настоящее время речь идет не столько о развитии сельских промыслов, сколько о их сохранении в условиям пандемии коронавируса.

Таким образом, развитие сельских промыслов в современных условиях обладает следующими характерными чертами:

1. Изменение структуры промысловой деятельности (на первый план выходит сельский туризм, ряд промыслов прекратили существование - лесозаготовка, судовой промысел и др.)

2. Появление интереса законодателя к сельскому туризму

3. Наличие объективной необходимости в введении промысловой деятельности с целью улучшения благосостояния сельского населения

\section{Библиографический список}

1. Закон РФ от 19.06.1992 № 3085-1 «О потребительской кооперации (потребительских обществах, их союзах) в Российской Федерации» (ред. от 02.07.2013) / Ведомости СНД и ВС РФ, 30.07.1992, № 30, ст. 1788.

2. Кандрина Е.В. Факторы, влияющие на возникновение и бытование традиционных народных промыслов и ремесел на территории поликультурного региона (на примере республики Мордовия) / Genesis: исторические исследования. 2019. № 8. С. 111-121.

3. Киркорова Л. А., Ларичева К. Н. Модернизация традиционных сельских промыслов / Вестник Новгородского государственного университета им. Ярослава Мудрого. 2014. № 82. С. 100-104.

4. Никулин В.Н. Крестьянские хозяйства Царскосельского уезда Санкт-Петербургской губернии на рубеже XIX-XX веков (земледелие и промыслы) / История: факты и символы. 2020. № 2 (23). С. 88-100.

5. Патрушева Г. М. Особенности организации сельского туризма и формирования турпродукта сельского туризма республики Алтай // Ученые записки (Алтайская государственная академия культуры и искусств). 2017. № 3 (13). С. 86-90.

6. Пономарева М.В., Чернобровкина А.О. Событийный агротуризм Тульской области / Российские регионы: взгляд в будущее. 2018. С. 58-80.

7. Проект Федерального закона № 690944-7 «О внесении изменений в отдельные законодательные акты Российской Федерации по вопросам развития сельского туризма (агротуризма)» / Доступ из СПС «КонсультантПлюс».

8. Сельское хозяйство, охота и лесное хозяйство [Электронный ресурс] / Росстат. URL: https://rosstat.gov.ru/ enterprise_economy (дата обращения 02.08.20).

9. Секерин В.Д., Горохова А.Е. Инновационная среда как фактор эффективности коммерциализации инноваций // Известия Московского государственного технического университета МАМИ. 2014. Т. 5. № 2 (20). С. 39-43

10. Секерин С.В., Веселовский М.Я., ГороховаА.Е. Учет экологического фактора при разработке инноваций // Вестник Астраханского государственного технического университета. Серия: Экономика. 2013. № 2. С. 163-168.

11. Филиппова Е.Н. Сельские подсобные производства и промыслы как экономическая категория / Вестник Алтайского государственного аграрного университета. 2012. № 2 (88). С. 140-144.

12. Филиппова Е. Н. Сельские промыслы в современной интерпретации / Агроинженерия. 2010. № 6. С. $114-117$.

13. Шмаков В. С. Модели развития сельских локальных сообществ / Никоновские чтения. Сельские территории в пространственном развитии страны: потенциал, проблемы, перспективы. 2019. С. 340-342.

14. Danko T.P., Ekimova K. V., Bolvachev A.I., Zarova E. V., Shemetkova O. L., Solovyova M. G., Sekerin V.D. ASSESSMENT OF THE COMPETITIVE POTENTIAL OF THE REGION THROUGH AN INTEGRATED SYSTEM OF RATING POSITIONING // International Journal of Economic Research. 2016. T. 13. № 6. C. 2361-2367. 
15. Tsenina E.V., Danko T.P., Ekimova K. V., Sekerin V.D., Gorohova A.E. INDICATION OF COMPETITIVENESS OF THE POTENTIAL OF THE REGION THROUGH HURWITZ AND WALD CRITERIA // Global Journal of Pure and Applied Mathematics. 2016. T. 12. № 1. C. 325-335.

16. Sekerin V.D., GorokhovaA.E., Dudin M.N., Shibanikhin E.A., BalkizovM.H. GREEN BUILDING: TECHNOLOGIES, PROSPECTS, INVESTMENT ATTRACTIVENESS // International Journal of Civil Engineering and Technology. 2018. T. 9. № 1. C. 657-666. 